九州大学学術情報リポジトリ

Kyushu University Institutional Repository

\title{
Meteorological Consideration on Trends of Atmospheric Sulphur Dioxide Concentration in London
}

Suzuki, Yoshinori

Laboratory of Agricultural Meteorology, Faculty of Agriculture, Kyusyu University

https://doi.org/10.5109/24047

出版情報：九州大学大学院農学研究院紀要. 38 (1/2)，pp.147-159，1993-12. Kyushu University バージョン：

権利関係 : 


\title{
Meteorological Consideration on Trends of Atmospheric Sulphur Dioxide Concentration in London
}

\author{
Yoshinori Suzuki \\ Laboratory of Agricultural Meteorology, Faculty of Agriculture, \\ Kyusyu University 46-05, Fukuoka 812, Japan \\ (Received August 10, 1993)
}

\begin{abstract}
A meteorological factor $\mathrm{F}$ (=Minimum temperature $\times$ Wind speed) is introduced to analyze trends of concentration of sulphur dioxide (y) in London after the Clean Air Act 1956. The relationship between the factor and pollution is linear, i.e. $\mathrm{y}=\mathrm{AF}+\mathrm{B}$, and the values of coefficient (A) and constant (B) depend upon fuel consumption and $\mathrm{SO}_{2}$ emission. The A-B diagram shows the relative level of SO, concentration for each year, taking account of effect of meteorological conditions. In central London, the trends of $\mathrm{SO}_{2}$ concentration change greatly in 1973 , the year of oil crisis.
\end{abstract}

\section{INTRODUCTION}

From the environmental point of view, London has a long history which troubled with severe air pollution caused by sulphur dixude and recorded one of the worst smog episode in the world in 1952. Since the enforcement of the Clean Air Act 1956, considerable attention has been given to its effect in London area. Although the reduction of smoke concentration was made clear by the Royal Commission on Environmental Pollution (1971), Warren Spring Laboratory (1972) and Chandler (1965), these studies present only a description of the trends without considering the effect of meteorological factors. In the comparing of air pollution year to year, we should consider effect of climate and social changes as well. This investigation analyzes the relationships between meteorological factors and atomospheric pollution, especially sulphur dioxide $\left(\mathrm{SO}_{2}\right)$ in London, and outlines trends of $\mathrm{SO}_{2}$ concentration since the Clean Air Act 1956 which was primarily introduced to control smoke emmision. The duration analyzed was limited to 1961-1976. The author think we should learn something from the history.

\section{MATERIALS AND METHODS}

Data on air pollution and meteorological element for London for period 1961-1976.

\section{Air pollution data}

Two sites were selected for Central London.

(1) Central London; the City

(2) Inner suburban London; Kew in the south-western part of London

The monthly average of daily values and the highest daily values of $\mathrm{SO}_{2}$ concentrations, measured during a month, were derived from daily observations made 
for the United Kingdom National Survey of Air Pollution. These data are published by Warren Spring Laboratory. According to the National Survey Site Classification, the City is DL, E, and Kew is B1, B2, where; DL: Commercial area or one with predominantly central heating, E: Smoke control area or Smokeless zone, B1: Residential area with medium-density housing, typically an inner suburb or housing, typically an inner suburb or housing estate, surrounded by other built -up areas, B2: Predominantly B1, but interspersed with some industrial undertakings.

\section{M eteorological data}

Monthy averaged values of nocturnal minimum temperature, daytime maximum temperature and daily mean wind speed for Kew derived from the Monthly Weather Report. Data for London Weather Centre (LWC), which is representative of the Central urban area were obtained from the Centre itself, as they are not published in the Monthly Weather Report.

\section{RESULTS}

\section{Pollution and meteorological elements: general characteristics}

Yearly changes of SO, concentration, daily minimum temperature and daily wind speed in London are shown in Fig.1.

(1) Atomospheric concentration

In the City, the maximum values of monthly averaged daily $\mathrm{SO}_{2}$ concentration

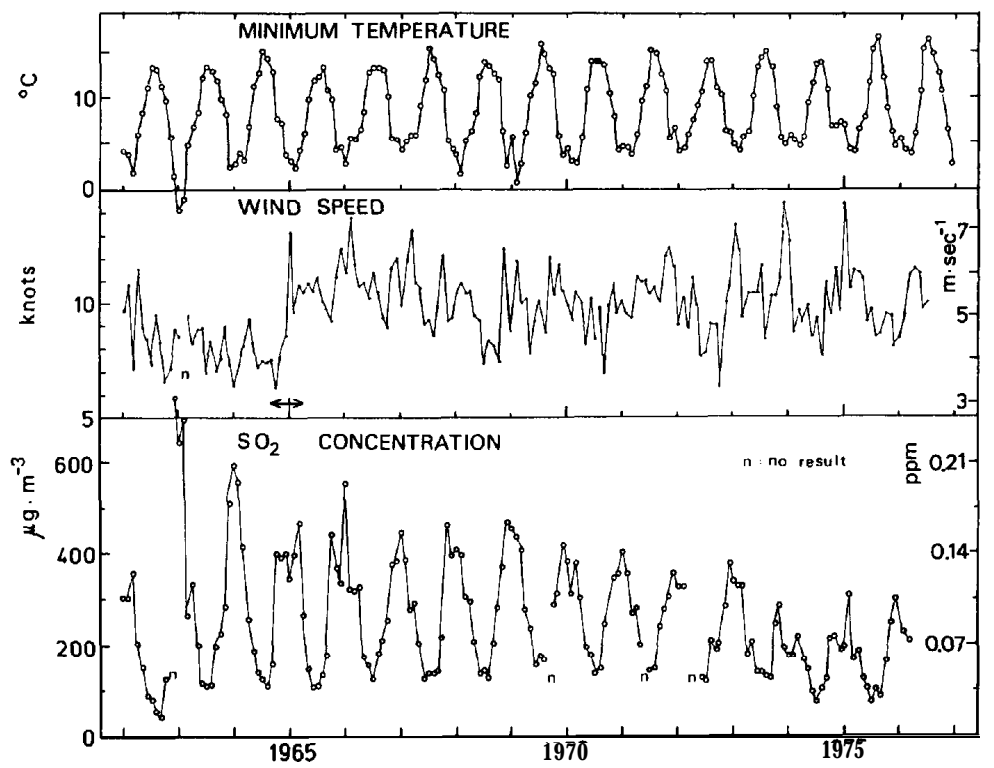

Fig. 1. Trends of minimum temparature, wind speed and $\mathrm{SO}_{2}$ concentration in Central London (the City \& LWC, 1962-1976). These are monthly mean values, which were used throughout all figures. 
decreased from year to year from the highest value of $740 \mathrm{gm}^{-3}$ in December 1962 to the lowest value of $300 \mathrm{gm}^{-3}$ in November 1973. On the other hand, the minimum value of each year did not show this decreasing tendency. In the period from 1963 to 1974, the minimum level remained between 100 to $120 \mathrm{gm}^{-3}$, but began to decrease to around $70 \mathrm{~g}$ $\mathrm{m}^{-3}$ after 1974. However, this last value was still higher than the minimum value in 1962.

At $\mathrm{Kew}$, the highest value of monthly averaged $\mathrm{SO}_{2}$ concentration of each year exceeded $300 \mathrm{gm}^{-3}$ during 1962 to 1964 , but no clear decrease occured after 1964 . The lowest values are generally around $30 \mathrm{gm}^{-3}$, but fell below this level in the first half of the 1960s. In contrast to the City, $\mathrm{SO}_{2}$ levels at Kew are both lower and do not display a clear seasonal variation. In fact monthly averaged concentration at Kew, are half as large and highest daily concentrations a quater as large as in the City.

The actual relations are as follows;

$$
\begin{array}{lll}
\text { Monthly averaged concentration } & y=2.2 x & \cdots(1) \\
\text { Highest daily concentration in a month } & y=1.5 x & \cdots(2)
\end{array}
$$

where, $x$ is the $\mathrm{SO}_{2}$ concentration at Kew, $\mathrm{y}$ is that in the City.

Relationships between monthly averaged value and the highest daily values of SO, concentration in a month are as fellows;

$$
\begin{array}{lll}
\text { the City } & \mathrm{HD}=2.4 \mathrm{M} & \cdots(3) \\
\text { Kew } & \mathrm{HD}=3.6 \mathrm{M} & \cdots(4)
\end{array}
$$

where, HD is the highest daily concentration and $\mathrm{M}$ is Monthly averaged concentration. The range of values of $\mathrm{HD} / \mathrm{M}$, however, is very wide from 1.6 to 5.2 for the City and from 2.2 to 6.2 for Kew. Those values are calculated for each month. It is not clear whether these coefficients have sesonal changes or depend upon wind speed.

(2) Minimum temperature

At the London Weather Centre, a progressive though slight increase in minimum temperatures (excluding seasonal variations of course> exists throughout the period 1963 - 1973. At Kew the summer half-year values show little change from year to year within the period. The winter half-values, however, show very large variation, falling to particulaly low values in 1963 and 1969 respectively. Comparing the winter half-year values in Central London with those in Kew, it appears that temperatures have relatively higher in Central London in to the 1970s.

(3) Wind speed

Monthly mean wind speeds vary fom 7 to $3 \mathrm{~ms}^{-1}$ at London Weather Centre and from 6 to $2 \mathrm{~ms}^{-1}$ at Kew with no clear seasonal variation other than from summer to winter; in general wind speeds are lower in summer than in winter. At both stations yearly changes of wind speed show a non-uniform pattern. The differences in absolute values of wind speed between LWC and Kew seem to be caused by the difference in measuring height and greater surface roughnes in the central urban area. At LWC, the measuring site was changed from Princess House (Roof $31 \mathrm{~m}$ above street level, the anemometer $12.5 \mathrm{~m}$ above the roof level) in Kingsway to State House (Roof $53.5 \mathrm{~m}$ above street level and the anemometer $16 \mathrm{~m}$ above the roof level) in Holborn in 1965 . As shown in Fig.1 measured wind speeds changed due to the change of height. According to parallel measurement at both sites from January to June 1965, the change of site lead to an increase in wind speeds of about $25 \%$ (Lee, 1975). 


\section{SO 2 concentration in relation to meteorological factors}

In the following analysis, the year starts in April and finishes in the following March.

(1) Relationship between $\mathrm{SO}_{2}$ concentration and minimum temperature

There seems to be an inverse relationship between $\mathrm{SO}_{2}$ concentration and monthly minimum temperature (Fig. 2) for each year, both in the City and at Kew; that is, the lower the temperature, the higher $\mathrm{SO}_{2}$ concentration. The relationships change from year to year as shown by the gradients of the straight lines. The gradients at Kew are smaller than those in the City throughout the priod. The reason for this are discussed later.

(2) Relationship between $\mathrm{SO}_{2}$ concentration and wind speed

There is clear relationship between and $\mathrm{SO}_{2}$ wind speed concentration (Fig. 3. A), which suggests that other factors such as minimum temperature are more important. Therefore, if we assume an inverse relationship between $\mathrm{SO}_{2}$ concentration and wind speed, we may obtain inverse proportion curves related to the value of $\left(\mathrm{SO}_{2} \mathrm{Conc} \times\right.$ Wind speed) (Fig. 3. A).

To investigate the role of wind speed, the relationship between the value of $\left(\mathrm{SO}_{2}\right.$ Conc. $X$ Wind speed) and minimum temperature was analysed (Fig. 3. B). Neglecting yearly changes for simplicity, there is a clear relationship between the two factors.

Figure 4 illustrates the association between $\mathrm{SO}_{2}$ concentration minimum temperatures and wind speeds for the period 1962 -1965. Values of SO, concentration are widely scattered, but they can be grouped on a curved line depending on the value of the factor (Min. temp. $X$ Wind speed) henceforth known as F.

This relationship may be expressed in the form,

$$
\mathrm{y}=\mathrm{C} /(x-\mathrm{A})+\mathrm{B}
$$

where, $x$ is wind speed and $\mathrm{y}$ is minimum temperature, while $\mathrm{A}, \mathrm{B}$ and $\mathrm{C}$ are constants which determine the positon of the curve for diffrent wind speeds and temperatures.

For simplicity, we may put $\mathrm{A}=\mathrm{B}=0$, then relationship will be $x \mathrm{y}=\mathrm{C}$.

Each of the curves may be considered to represent, albeit indirectly, a given capacity for atmospheric diffusion. The validity of this view lines in accepting that minimum temperature is clearly related to atmospheric stability. When surface minimum temperature is low, the boundary layer tends to be stable, and mixing layer is small. Also when minimum temperature is low, domestic heating tends to be great, so, minimum temperature relates to both the atomospheric environment and the activity of $\mathrm{SO}_{2}$ emission source. On the other hand, wind speed relates to diffusivity of air pollutants as follows: if wind speed is low, so is deffusivity and similarly high wind speeds and high diffusivities go together. Therefore, a combination of minimum temperature and wind speed will cause the following relations: if minimum temperature and wind speed are low, diffusivity is low and emissions high: or if minimum temperature and wind speed is high, deffusivity is high and emissions low. So, when F is low, diffusivity is low, or when $\mathrm{F}$ is high, diffusivity is high. To confirm these suggested qualitative relations, additional quantitative information is necessary.

As an indirect measure of the atomospheric stability, the temperature difference at noon between the $1000 \mathrm{mb}(=\mathrm{hpa})$ and $850 \mathrm{mb}(=\mathrm{hpa})$ levels was calculated for some selected data during the period 1962-1975. In and around London, there is only one 

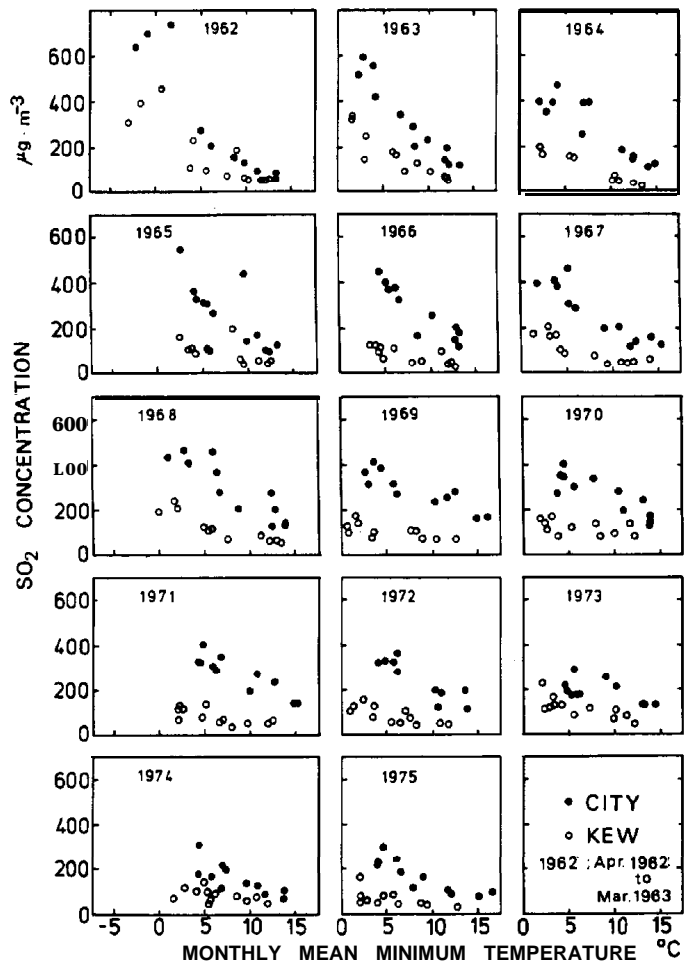

Fig. 2. $\mathrm{SO}_{2}$ concentration vs minimum temperature in the City and Kew.
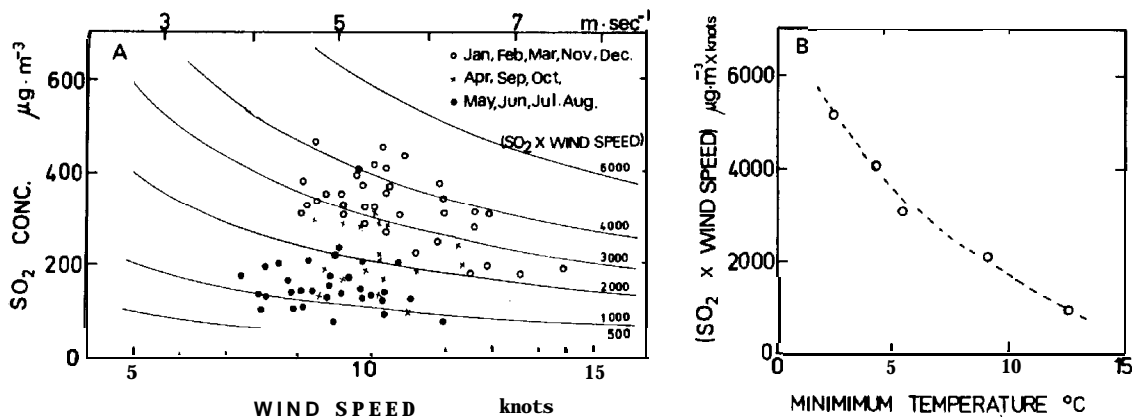

Fig. 3. A. $\mathrm{SO}_{2}$ concentration vs wind speed (LWC, 1962-1976).

B. $\left(\mathrm{SO}_{2} \mathbf{x}\right.$ wind speed) value vs minimum temperature (LWC, 1962-1976).

station, Crawley, some $35 \mathrm{~km}$ south of central London, which observes the vertical distribution of air temperature. The significance of meteorological factor $\mathrm{F}$ at LWC and Kew is examined using the potential temperature gradient at Crawley. The relationships between potential temperature gradient $\left(\mathrm{A} \mathrm{T}{ }^{\circ} \mathrm{C} / 15 \mathrm{Omb}(=\mathrm{hpa})\right.$ ), mimimum temperature and $\mathrm{F}$ are shown in Fig. 5. A, B. Both minimum temperature and F show fairly strong correlation with atmospheric stability, but in the case of the former, LWC shows a poorer fit than Kew. 


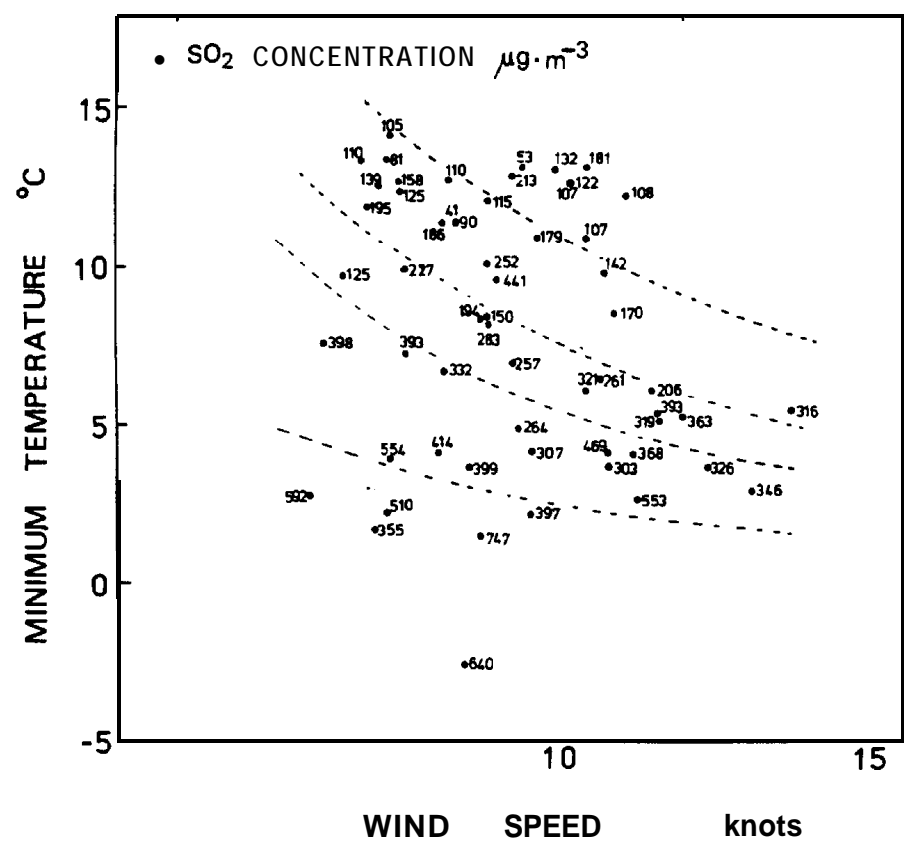

Fig. 4. $\mathrm{SO}_{2}$ concentration plotted against minimum temperature and wind speed (Central London 1962-1976). Dotted line is a constant of (minimum temperature $\mathrm{X}$ wind speed).

Analysis of characteristics of yearly changes of $\mathbf{S O}_{2}$ concentration

In the previous section, it was found that $\mathrm{F}$ is a good index of diffusivity of $\mathrm{SO}_{2}$ gas in the atmospheric environment in London. Hence, this factor is used to analyse yearly changes of $\mathrm{SO}_{2}$ concentration in the period $1962-1976 . \mathrm{SO}_{2}$ concentrations are plotted against $\mathrm{F}$ for each of the 12 months from April to the following March. Fig. 6 shows linear relations between them at both $\mathrm{Kew}$ and in the City. $\mathrm{SO}_{2}$ concentration is inversely proportional to $\mathrm{F}$, and the gradient of the straight line is gratest for the 1963 data decreasing strongly in the 1970 s data. The value of the Y-axis intercept, that is, the value of $\mathrm{SO}_{2}$ when $\mathrm{F}$ is zero, decreased year by year. If the environmental conditions are the same and the amount of $\mathrm{SO}_{2}$ emission does not change, then the $\mathrm{SO}_{2}$ concentration should be same in the atmosphere. When differences in $\mathrm{SO}_{2}$ concentration exist under similar environmental conditions, the amount of near-surface emission is considered to have changed.

The straight line for each the 12 months in Fig. 6 is expressed in the equation

$$
\mathrm{y}=\mathrm{A} x+\mathrm{B}
$$

where, $\mathrm{y}$ is $\mathrm{SO} 2$ concentration, $x$ is $\mathrm{F}$. A is coefficient and $\mathrm{B}$ isconstant.

To clarify the yearly changes of $\mathrm{SO}_{2}$ concentration, the value of gradient (A) were plotted against value of the Y-axis intercept (B) in Eq. (6) (Fig. 7). This relationship is called the A-B diagram. (A) has a close relation to (B), and the point $(\mathrm{A}, \mathrm{B})$ in the AB diagram becomes close to the origin with change of yeear from 1962 to 1975. In Fig. 
7, the data using corrected wind speed for the change of height are also given for 1962, 1963 and 1964. There is a difference in the shape of the graph, however, both of uncorrected and corrected years are grouped in the same line consisting of the periods from 1962 to 1972 . A great change in this relation seemed to occur in 1973 in central London. The relationship at Kew is different from that of Central London. This will be discussed later.

Judging from the shape of the curved line, it is estimated that the gradeint (A) will meet in zero and B will meet in a non -zero value. This non - zero value may be considered to be background value, which remains constant from season to season. This background level for the U.K. and West Europe will be about $15-25 \mathrm{~g} \mathrm{~m}^{-3}$. The difference in the shape of the curves between Kew and LWC is due to the difference in the constant B. This may be caused by the lower emission of SO, in the Kew area. The value (A) for Central London in 1973 is nearly equal to that of Kew in the period 19651968. Even if the gradient (A) is equal in both sites, the value B is quite different. On the assumption that the atmospheric environment is the same at both station, this difference must be due to emission of $\mathrm{SO}_{2}$ around the City.

\section{Emission of $\mathrm{SO}_{2}$, fuel consumption and $\mathrm{SO}_{2}$ concentration}

Clearly, emission have an effect upon SO, concentrations. This section deals with $\mathrm{SO}_{2}$ sources in the London Region. $\mathrm{SO}_{2}$ emission showed its peak in the first half of the 1960s (Fig. 8. A, B). Emission in the 1970s, however, did not always decrease at a rate greater than that in the last half of the 1950s. Of the fuels which release $\mathrm{SO}_{2}$ in
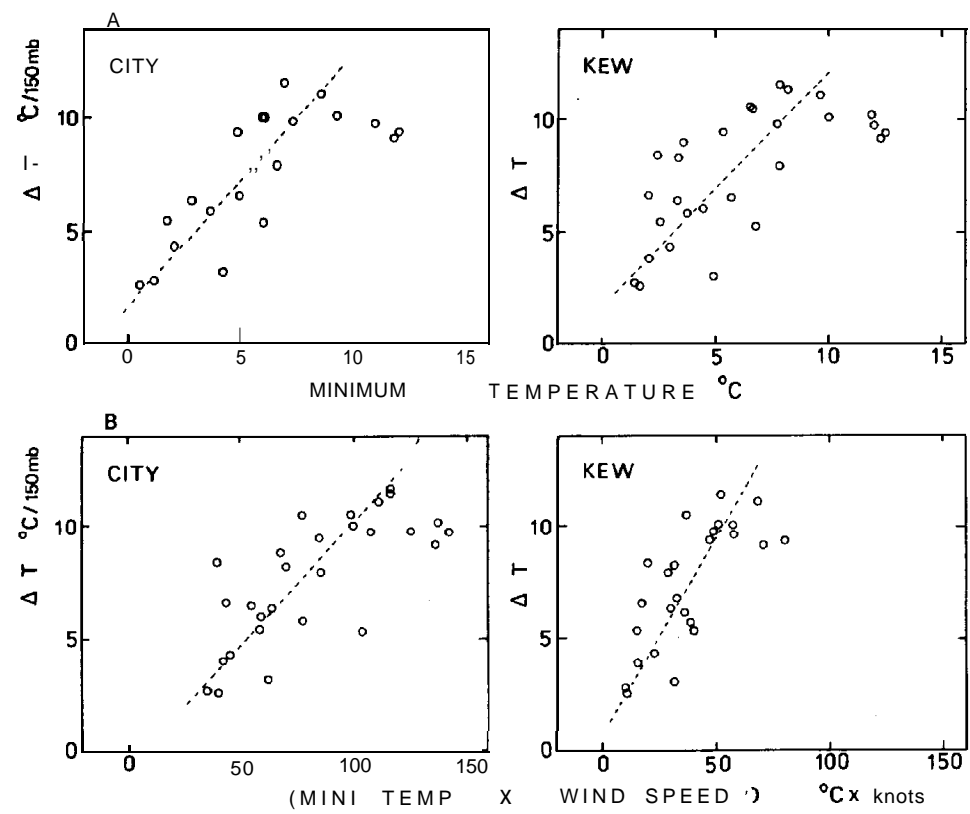

Fig. 5. A. The temperature gradient $(\triangle T)$ between the height at $1000 \mathrm{mb}(\mathrm{hPa})$ and at $850 \mathrm{mb}(\mathrm{hPa})$ vs minimum temperature. Data of vertical distribution were measured at Crawley.

B. $\triangle \mathrm{T}$ vs the factor $\mathrm{F}$ (minimum temperature $\mathrm{x}$ wind speed). 

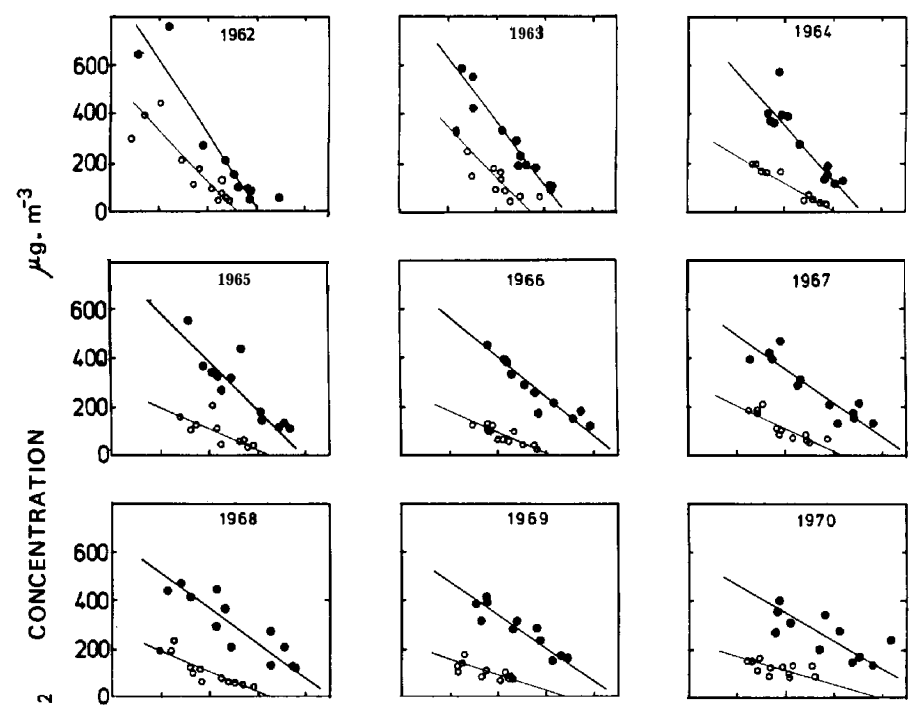

is
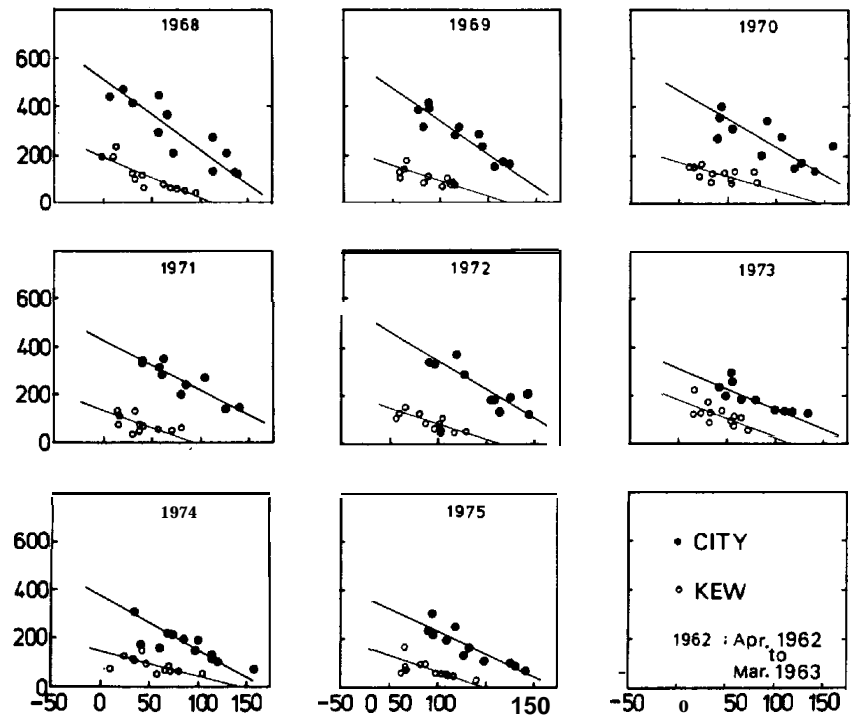

(MINI TEMP $X$ WIND SPEED)

${ }^{\circ} \mathrm{C} x$ knots

Fig. 6. SO, concentration vs factor $\mathrm{F}$ in Central London and Kew.

combustion, the main one was coal in the early 1960 s, but since 1965 , oil has become predominant.

There is no clear linear relationship between them, due to the difference of sulpur content in different types of fuel. But, it may be pointed out in general that $\mathrm{SO}_{2}$ emission was proportional to fuel consumption and $\mathrm{SO}_{2}$ emission rate decreased in the years from 1965 to 1968 .

To compare with the yearly amount of $\mathrm{SO}_{2}$ emission, the average $\mathrm{SO}_{2}$ concentration was calculated for the calendar year in contrast to the year April to March as used earlier. The arithmetic mean of Kew and the City data was condidered to be representative of the Greater London's mean (Y.M), because the City has probably one of the highest values and on the other hand Kew has one of the lowest values of $\mathrm{SO}_{2}$ concentration in Greater London. Then, the yearly mean of the highest daily $\mathrm{SO}_{2}$ concentration was compared with the yearly amount of $\mathrm{SO}_{2}$ emission. In this case, the 
value was also the arithmetic mean of Kew and the City. The resultes are shown in Fig. 9. It is clear that the $\mathrm{SO}_{2}$ concentration in urban atmosphere depends on the amount of $\mathrm{SO}_{2}$ emission.

The linear regression formulae are;

For the mean value of $\mathrm{SO}_{2}(\mathrm{Y} . \mathrm{M}) \quad \mathrm{y}=0.5 x \mathrm{i}-20 \quad \cdots(7)$

For the highest value of $\mathrm{SO}_{2}$ (Y.HD) $\mathrm{y}=1.8 x-161(x>250) \quad \cdots(8)$

where, $\mathrm{y}$ is $\mathrm{SO}_{2}$ concentration $\left(\mathrm{gm}^{-3}\right)$ and $x$ is $\mathrm{SO}_{2}$ emission $\left(x 10^{3}\right.$ tons). For the highest value (Y.HD), there is a conflict in the linear regression formura in the low range under 200 ( $x 10^{3}$ tons) of $\mathrm{SO}_{2}$ emission. Because the condition of Y.HD > Y.M is the necessary in the whole range of $\mathrm{x}$.

Sources of $\mathrm{SO}_{2}$ emission are distributed widely in the whole region of London, hence there some sources which do not effect the $\mathrm{SO}_{2}$ concentration at Kew or the City under some wind direction. A tendency between them is suggested by this analysis. As shown in Fig. $10 \mathrm{~B}$, coefficient (A) is considered to depend upon emission of $\mathrm{SO}_{2}$ as the emission of $\mathrm{SO}_{2}$ per year decreases, the absolute value of the coefficient, $\left(\mathrm{SO}_{2} / \mathrm{F}\right)$ decreases. The difference of slope of the straight lines and shape of curved line in Kew and City is due to the difference in their location within the built-up area of London. It

B

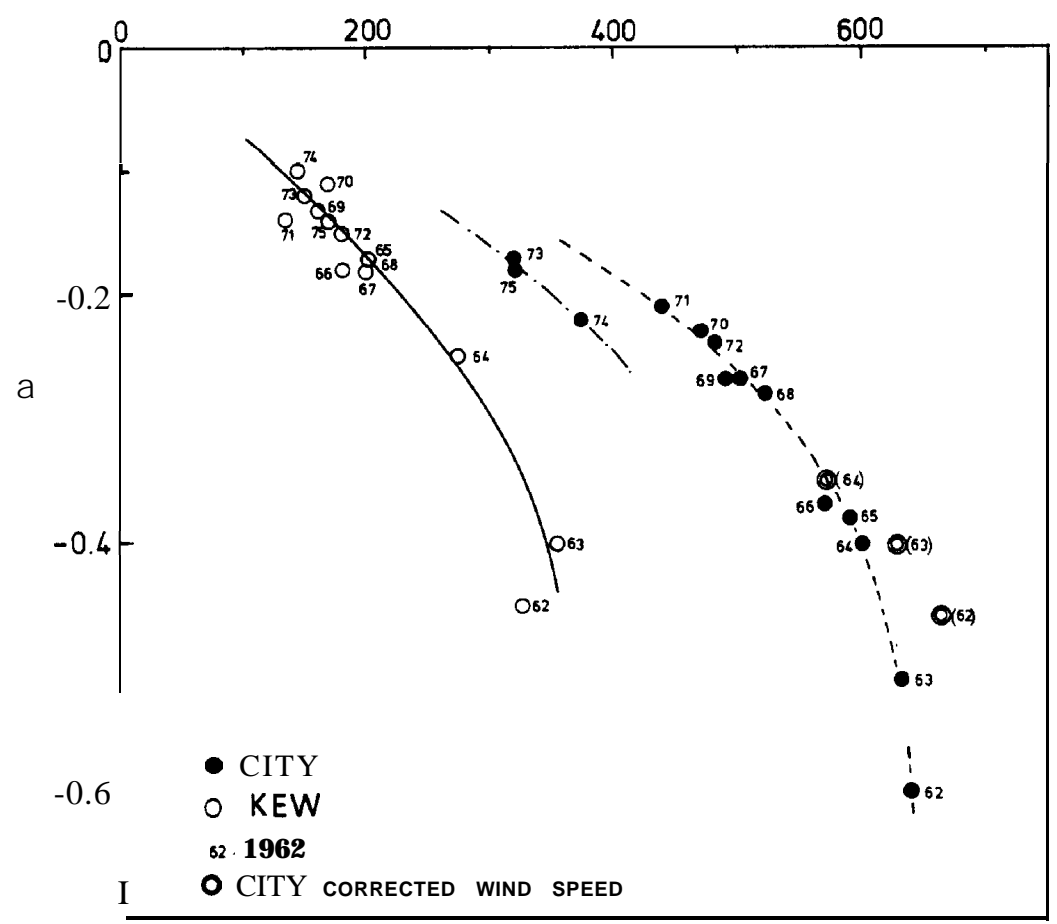

Fig. 7. A-B diagram. Relation between coefficient $A\left[\mathrm{SO}_{2} /(\mathrm{MIN}\right.$. TEMP. $\times$ WIND SPEED)] and constant B for Central London and Kew. The figure shows the year of 1900s. 

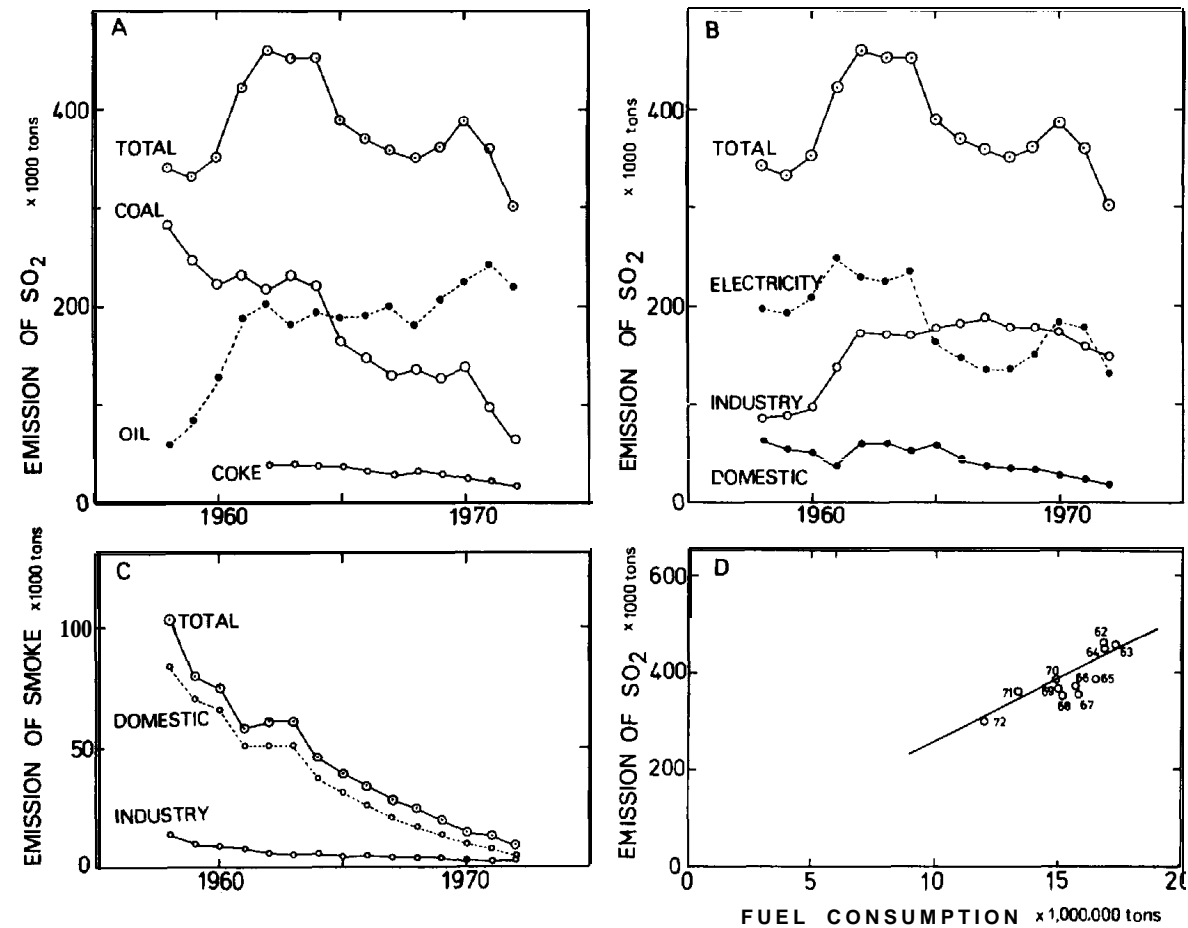

Fig. 8. A \& B. Trends of emission of SO, in Greater London Region. (A: Kinds of fuels, B: Kinds of users).

C. Trends emission of smoke in Greater London Region.

D. Relationship between fuel consumption and emission of $\mathrm{SO}_{2}$ in Greater London Region. The figure shows the year of 1900s.

is suggested that emission from the whole area does not always effect equally each site relating to wind direction. If we take the amount of $\mathrm{SO}_{2}$ emission in the narrow region with a radius of 3-4 $\mathrm{km}$ around Kew or the City, the relationships would undoubtedly be clearer.

\section{DISCUSSION}

The aim of the Clean Air Act 1956 was to reduce the concentration of smoke rather than sulphur dixide. If smoke emission is associated with $\mathrm{SO}_{2}$ emission, there may be a possibility that $\mathrm{SO}_{2}$ concentration also may be effected by the Act. In London as a whole, smoke control came into force in 1st October 1958 under the Clean Air Act 1956. In the City, on the other hand, smoke control commenced on 1st October 1955 under the City of London Act 1954. The proportion of premises covered by smoke control order in Greater London Region grew slowly from $56.0 \%$ at the end of 1967 to $87.8 \%$ in 1974 . In the City, $100 \%$ smoke control was achieved before 1958 .

From the above analysis based on monthly and annual means, it is found that the 


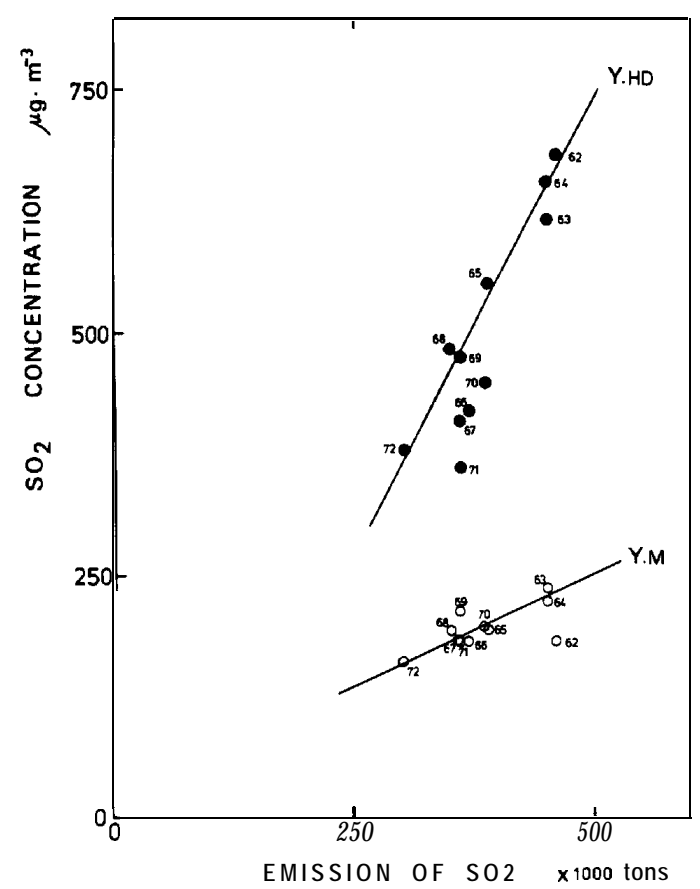

Fig. 9. Emission of $\mathrm{SO}_{2}$ in Greater London Region vs averaged $\mathrm{SO}_{2}$ concentration between the City and Kew. Y.M. is yearly mean of SO, concentration, and Y.HD is yearly mean of monthly highest daily value of $\mathrm{SO}_{2}$ concentration. The figure shows the year of 1900s.

value of $\mathrm{F}$ is suitable for a quantitative index of meteorological conditions in relation to $\mathrm{SO}_{2}$ concentration in London. Inverse relationships between $\mathrm{F}$ and $\mathrm{SO}_{2}$ concentration are found. From this relationship, the A-B diagram is derived and shown in Fig. 7. The point $(\mathrm{A}, \mathrm{B})$ in this figure is an important index for judging trends of $\mathrm{SO}_{2}$ concentration in London. By tracing these points, we can estimate the relative level of $\mathrm{SO}_{2}$ pollution for any year by comparing it with the other years having taken account of the effects of meteorological conditions. When the point $\mathrm{A}$ is close to the origin, $\mathrm{SO}_{2}$ concentration becomes small and the effect or the activity of the source decreases. This position for each year since 1962 is close to the origin, associated with $\mathrm{SO}_{2}$ emission as shown in Fig. 10 and Fig. 11. But in the City, this tendency changed greatly in 1973. This suggest that a significant change in the activity of fuel consumers took place during this period. This change in the City may be a reflection of the oil crisis. Although SO, concentrations in Central London became small, they remained at a rather high level relative to those in inner suburban London in the first half of the 1970s. Even in the City, where $100 \%$ smoke control had been achieved in 1958, atmospheric pollution by $\mathrm{SO}_{2}$ is still significant, presumably due to advection of pollutions from surrounding areas. It was not until 1973 that the improvement on reducing $\mathrm{SO}_{2}$ concentration became clear in the City. 

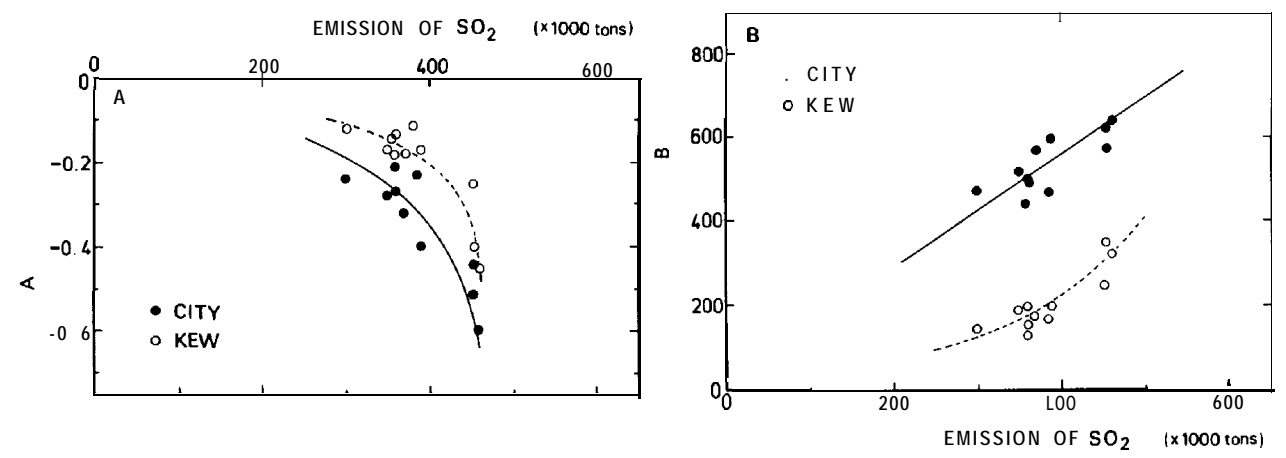

Fig.10. Emission of SO, in Greater London Region vs coefficient A (left) and constant B (right) for the City and Kew.
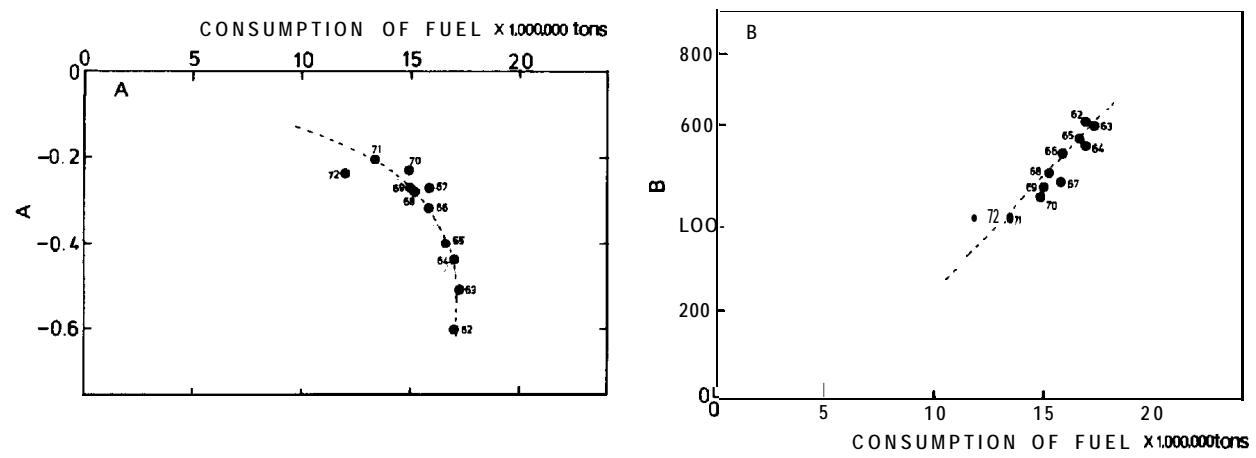

Fig. 11. Consumption of fuel in Greater London Region vs coefficient A (left) and constant B (right) for the city. The figure shows the year of 1900s.

\section{CONCLUSION}

An analysis is presented of the trends of sulphur dioxide concentration in London since the Clean Air Act 1956 in relation to two meteorological factors. The study sites are the City, Central London and Kew, inner suburban London. The data used are monthly and yearly means. The results are summarized as follows;

1. The magnitude of $\mathrm{SO}_{2}$ concentration is inversely proportional to minimum temperatures for each year as a whole.

2. The magnitude of $\mathrm{SO}_{2}$ concentration (y) is inversely proportional to a meteorological factor $\mathrm{F}$ ( $\mathrm{min}$ temp. $X$ wind speed) and may be expresses in a formula of the form $\mathrm{y}=\mathrm{AF}+\mathrm{B}$ for both Kew and the City.

3. The meteorological factor $\mathrm{F}$ has a close relationship with atmospheric stability.

4. Using this factor $\mathrm{F}$, the yearly variation of climate can be taken into account.

5. The coefficient $\mathrm{A}$ and constant $\mathrm{B}$ give the characteristic point for each year in the A-B diagram, which show the level of the trends of SO, concentration. 
6. The value $[\mathrm{A}]$ and $[\mathrm{B}]$ depend upon fuel consumption or $\mathrm{SO}_{2}$ emission in London Region.

7. After the enforcement of the Clean Air Act 1956, $\mathrm{SO}_{2}$ concentration in London has been reduced as well as smoke concentration in London, but in Central London it was not until 1973 that improvement on reducing $\mathrm{SO}_{2}$ concentration became clear. This corresponds to the time when the oil crisis occured.

\section{ACKNOWLEDGEMENTS}

I wish to thank Dr. D.O. Lee of Birkbeck College and Dr. B.W. Atkinson of Queen Mary College, University of London fot their help throughout the completion of this project and Miss K. Cho of Kyushu University for her assistance in wordprocessing.

\section{REFERENCES}

Chandler T.J. (1965); The climate of London. London, Hutchinson \& Co. 292pp.

Greater London Council (1965-1974); Annual Abstract of Greater London Statistics, Vol. 1 -Vol. 9. Lee D.O. (1975); A study of the influence of surface roughness and tempereture of cities on urban airflow. Unpublished, Ph.D Thesis of Univ. of London, pp62.

Meteorological Office (1962 - 1976) ; Monthly Weather Report, Vol.79 - Vol.94.

Warren Spring Laboratory (1961-1976); The investigation of air pollution, national survey smoke and sulphur dioxide.

Warren Spring Laboratory(1972); National Survey of Air Pollution 1961-1971, Vol. 1, HMSO, $195 \mathrm{pp}$. 